Historic, Archive Document

Do not assume content reflects current
scientific knowledge, policies, or practices. 


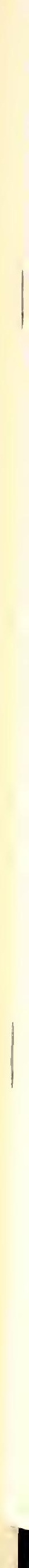




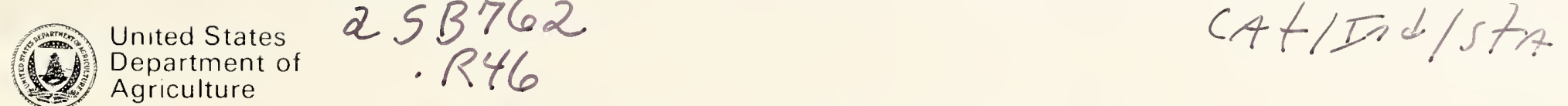

Forest

Service

Forest Pest

Management

Methods

Application

Group

Fort Collins,

Colorado 80524

(4iss

INTEGRATED PEST IMPACT
ASSESSMENT SYSTEM DEVELOPMENT:
IMPACT MODEL INVENTORY AND USE SURVEY
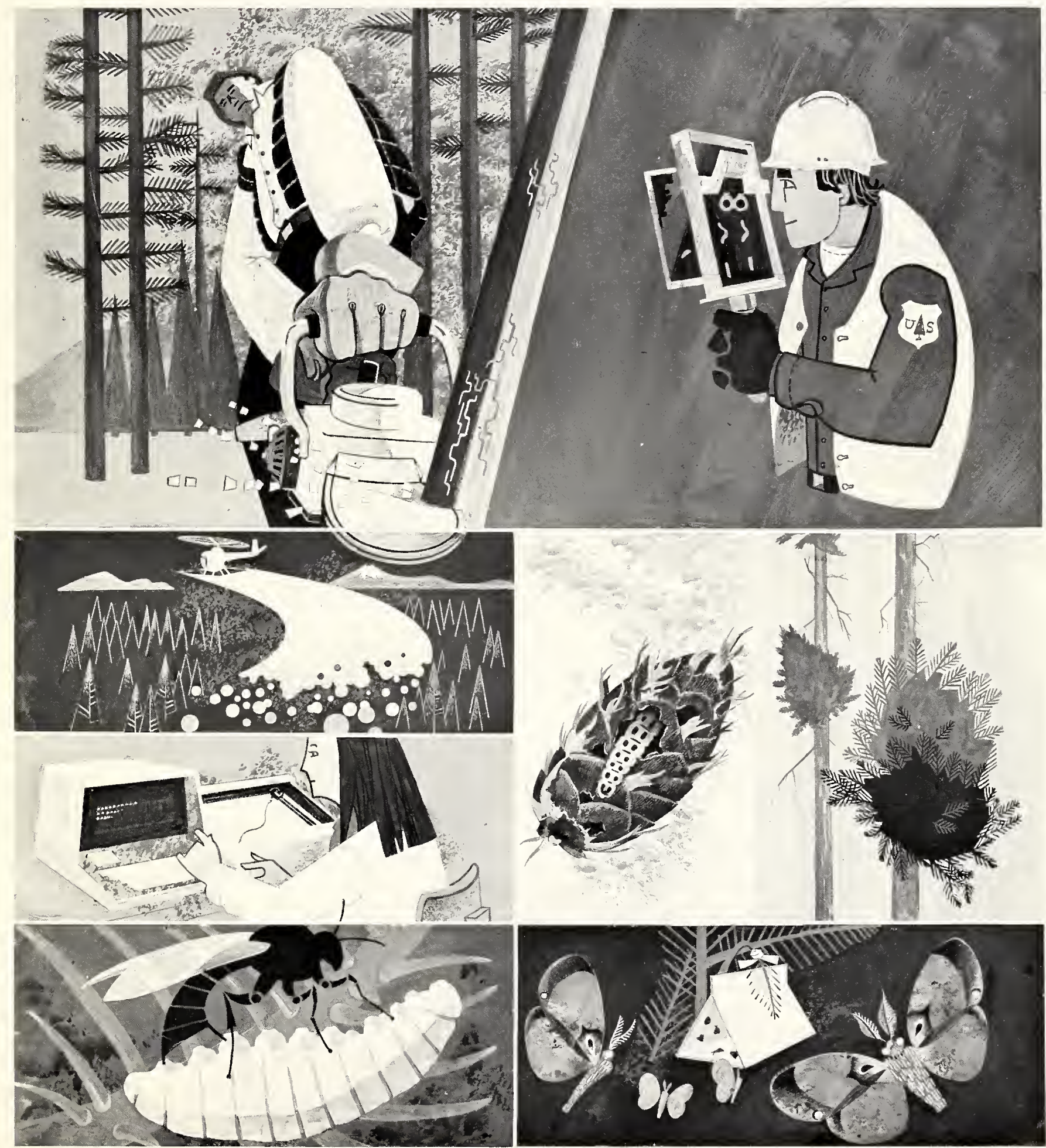
AD-33 Bookplate

$(1-8)$

\section{NATIONAL}

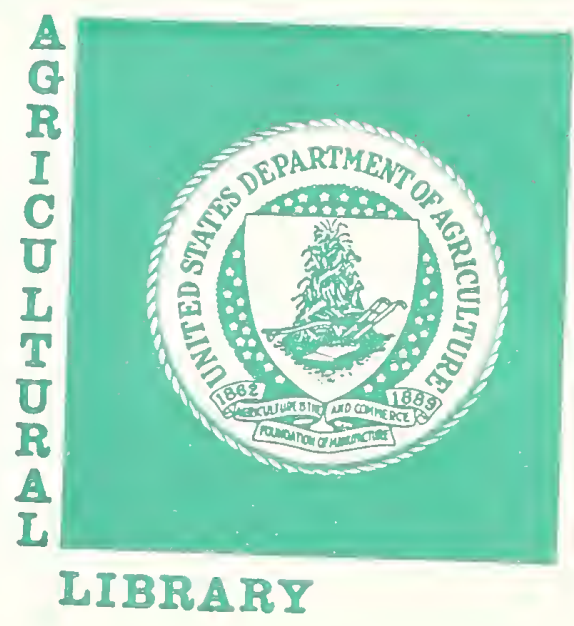


Report No. $86-5$

INTEGRATED PEST IMPACT ASSESSMENT SYSTEM DEVELOPMENT: IMPACT MODEL INVENTORY AND USE SURVEY1/

by

G.J. Buhyoff, T.C. Daniel, W.B. White, and D.O. Hunter2/

\section{ABSTRACT}

The first phase of the development of an expanded Integrated Pest Impact Assessment System (IPIAS) was an inventory of forest stand, pest and other forest resource impact models. Models were evaluated for their applicability to the IPIAS concept in which models would be linked to provide management information about predicted impacts of forest pests. A survey of potential users of IPIAS was conducted in conjunction with this inventory. This survey solicited opinions about current impact model use as well as future model needs. Results of these efforts indicate both a need for IPIAS and the existence of a potentially useful base of models for development of IPIAS.

\section{INTRODUCTION}

The development of an expanded Integrated Pest Impact Assessment System (IPIAS) is to be accomplished over a period of several years (Daniel et al. 1983). The goal of IPIAS is to provide forest planners and managers with an efficient and effective means for projecting the socioeconomic and biological impacts of pest outbreaks and alternative management actions designed to reduce losses. The system will not only focus upon the effects of forest changes associated with pest damage and control, but will also be applicable

$1 /$ The work described herein was funded in whole or in part by USDA Forest Service, Forest Pest Mangement/Methods Application Group, as part of a five year project - Integrated Pest Impact Assessment System (IPIAS). Cooperative Research Agreement (No. 28-C4-320) between Rocky Mountain Forest and Range Experiment Station for MAG, and Virginia Polytechnic Institute and State University, details the specific objectives and funding for this project.

2/The authors are respectively: Professor of Biometrics, Virginia Polytechnic Institute and State University, Blacksburg, VA; Professor of Psychology and Renewable Natural Resources, University of Arizona, Tucson, AZ; Entomologist, USDA Forest Service, Forest Pest Management/Methods Application Group, Fort Collins, CO; and Ecologist, Western Energy and Land Use Team, U.S. Fish and Wildlife Service, Fort Collins, Co. 
to a much wider range of forest management problems (actions which cause stand modification).

A major project objective is to enhance IPIAS with a geographic information system (GIS) which would serve as the input data base for stand growth and impact models. The geographic information system should allow the user to quickly input specific stand data and area and spatially evaluate the current resource. IPIAS, then, will for several time periods, take one initial stand, modify it by way of a growth simulator model, a pest outbreak model, and a given management prescription and then output the characteristics of the residual stand at each time period. These data can then be used as inputs to impact models of various types.

\section{OBJECTIVES}

A logical starting point in the development of such a system is the identification of currently avallable pest impact models and the assessment of user opinions of these and other related models. In fact, a 5-year research and development project for IPIAS (Anonymous 1983) charts a course of action which includes these tasks. Some of the major areas of development specified by this document are: (1) survey and evaluate models now in use, and (2) identify model information currently used and additional information needs. More specifically, a cooperative research agreement (No. 28-C4-320) with Virginia Polytechnic Institute and State University and the University of Arizona specified that the following detailed objectives were to be accomplished in Fiscal Year 1984 as the first stage of IPIAS development:

1. Conduct a search for forest stand and socioeconomic impact models.

2. Conduct a search for mountain pine beetle models.

3. Survey pest management and research groups for mountain pine beetle models currently being used or developed.

4. Report on existing forest stand and mountain pine beetle models, including types of data needed and types of output produced.

5. Identify potential users of IPIAS.

6. Identify impact information currently used by these groups and how it is used.

7. Identify additional information user groups would like to have.

MODEL INVENTORY AND ASSESSMENT

To develop a solid basis for the extension of IPIAS, a comprehensive evaluation was conducted (Appendix A) of currently available pest impact and other forest prediction models which might be candidates for IPIAS application 
in targeted demonstration areas (USDA Forest Service Regions 1 and 6). Models were identified and evaluative criteria developed based on intensive interviews with Forest Service personnel in the Washington office, Forest Research Stations, and Region 1 and 6 staffs. A total of 55 individuals, all familiar with the development and use of models for forest management and planning, were contacted in this model evaluation phase. As a result, 46 separate models or model extensions were identified and evaluated for their potential usefulness to IPIAS and were entered into a computer data base management system for quick reference and update. Documentation was obtained for these models and where necessary, individuals who could clarify model use were contacted. Thirty-one of the models were deemed as meeting the broad criteria of either generalized applicability to Regions 1 or 6 , or applicability to lodgepole pine (Table 1). These models also had to be useful in assessing impacts as the result of mountain pine beetle infestations or in making predictions regarding the behavior of such infestations. $\underline{3}$ / The models did not have to be applicable to all four criteria. This was not merely a literature search since the total effort described here included analysis of the models as to their applicability to IPIAS as well as an evaluation of each models potential interfaceability to a broader network of impact models as required by IPIAS. Each of the models were evaluated for application region, stand and species type, input data requirements, output data requirements, limitations and constraints, extensions and modifications, and indications of validity testing.

The remainder of the 46 models were also comprehensively evaluated but not included in the data base since their applicability to IPIAS was determined to be minimal or nonexistent because their primary use was in places other than Regions 1 or 6 . These included: INVEST III, MULTIPLOY, Budworm Evaluation Mode1, MTVEST, MAX2, RAMPREP, ECHO, SIMAC, and SORAC. In addition to the 46 models, 32 other trend prediction, management simulation, hazard rating, and spot growth models specific to southern pine beetle were researched and assessed as to their potential applicability to IPIAS (Table 2). These models are summarized in Mason (1984). Again, these models were, however, not directly applicable to the development of IPIAS in Regions 1 and 6 . During this model identification phase, several other quantitative impact models were found. However, these models were discovered to be "only guidelines", "under development", "not tested", "currently being debugged", "not widely applicable", or in some cases, only rumored and did not actually exist. The final 31 models which were selected as being potentially useable in IPIAS can be broken down into categories for which they make predictions, conduct efficiency analyses, or perform simulations (Table 1). The categorizations in Table 1 are one way of assessing prevalence or absence of certain types of models. Note that some models appear under more than one category since they perform more than one type of prediction or analysis.

3/Copies of this data can be obtained by writing G.J. Buhyoff, Professor of Forest Biometrics, School of Forestry and Wildlife Resources, Virginia Polytechnic Institute and State University, Blacksburg, VA 24061. 
Table 1 - Models Evaluated for use in IPIAS.

Growth and Yield

PROGNOSIS

TRAS

FREP/STEMS

TWIGS

TRIM

ECOSIM

GROW

DFSIM

INDIDS

TREES

R2GROW

RMYLD

\section{Insect/Pest}

Dwarf Mistletoe

Mountain Pine Beetle

TREE LOSS FROM MOUNTAIN

PINE BEETLE INFESTATIONS

INDIDS

LP-DM-V OL

PROGNOSIS extensions:

Western Spruce Budworm

Douglas-Fir Tussock Moth
Economic Efficiency

CHEAPO

FORESTRY INVESTMENT ANALYSIS

TRIM

DPDF SIM

LP-DM-V OL
Harvest Scheduling

TREES

PROGNOSIS extension:

EVENT MONITOR

\section{Wildlife}

ECOSIM

PROGNOSIS extension:

COVER HABITAT SUITABILITY

INDEX MODELS

ELK HABITAT MODEL
Hydrology

ECOSIM

SREAM SEDIMENTATION

(Effects on Salmond Habitat)

Comprehensive Simulations

ECOSIM

IMPLAN

DEBMOD

Debris

MICRO I/O

It is particularly noteworthy that no range, recreation use, or visual quality models are listed. Current approaches to the assessment of impacts on "other" forest resources such as social impacts tend to be more qualitative than quantitative and rely on expert judgment rather than explicit analytical systems despite the fact that the technology exists to formulate such models.

The wildife category displays models which can aid wildlife impact predictions; however, one is specifically incorporated in the ECOSIM model itself and another (PROGNOSIS, COVER extension) makes projections of changes in shrubs and canopy which can potentially be used as input for specific wildlife population models. A single quantitative model for the prediction of elk movement was found for the target regions. Also, a comprehensive set of wildlife "impacts" developed by the Western Energy and Land Use Team (WELUT) of the U.S. Fish and Wildife Service, were also identified. These models, 
Table 2 - Southern pine beetle prediction models evaluated for possible integration with IPIAS I/

Trend Prediction Models

SPB COMP

AERIAL GA

SOUTHEAST SURVEIL

SOUTHEAST PREDICT

NC SURVEIL

NC PREDICT

NC PIED SURVEIL

NC PIED PREDICT

GA SURVEIL

GA PREDICT

FRONS IM

DAMBUGS $\underline{\text { Hazard Rating Models }}$

TFS GRID HAZARD

AR HAZARD

MS HAZARD B

SADER HAZARD

$P$ HAZARD GA

TX HAZARD

WEST GULF HAZARD

NF RISK

PIEDMONT RISK

MOUNTAIN RISK

WEST GULF PROB

COAST PROB

PIED PROB

Spot Growth Models

TAMBEETLE

ARKANSAS SPB

TFS SPOT GROWTH

EA Ratio

1/From Mason (1984; revised June).

referred to as Habitat Suitability Index (HSI) models, project impacts on wildife and fisheries species by predicting habitat suitability (as an 0-1 index) resulting from changes in that habitat. These HSI models appear to be of the type suitable for IPIAS. From our research it seems that "rules of thumb" are more prevalent than mathematical formulations for making predictions of changes in wildiffe levels. For example, Thomas (1979) details many descriptions of habitat types which support various bird and wildiffe species.

USE OF MODELS IN IPIAS

The models presented in Table 1 are representative of model components that might be used in Region 1 or 6 IPIAS. IPIAS is not intended to be a single set of models to be used in all locations or situations. Rather, IPIAS is intended to be a framework for a computer assisted forest pest management information system that can link together (1) biological (including forest 
growth and mortality, yield, and pest effects); (2) economic (stumpage values, management costs, and local and regional economic effects); and (3) social impact (recreation, scenic beauty, and wildlife) components. IPIAS will provide information assimilation and presentation rather than optimization. It is not, by itself, a decisionmaking system. Because of its modular design and its use of forest characteristics as a basic input to all impact modeling IPIAS can be used to address a wide range of forest management problems for a specific application area (a major drainage). Thus, the comprehensive model inventory and evaluation presented here and in Buhyoff and Daniel (1984) provides information necessary for determining what components can be "pulled off the shelf" to be linked into IPIAS for a particular geographic forest management unit application.

At this stage of the IPIAS development program it is difficult to further define the exact linkages and use of the models in IPIAS. While it is obvious that growth and yield models are different in their inputs/outputs from economic efficiency and other models, ultimate use of any of these models and the resultant use of them by IPIAS can only be meaningful given specific user needs. At the simplest level they are all prediction techniques; however, while we know they predict different parameters, they also do so in different ways. Some of the models listed are simulations, others are optimization models. Also, they make predictions over different time frames, geographical areas and for different stand types. Since the primary intent of IPIAS is to be a management information rather than a management decision system, the basic IPIAS framework will not ordinarily provide linkages to optimization models but only to impact models. However, should a set of users wish optimization model linkages, these can be defined and constructed.

The question of geographic scale of the predictions is also critically involved in evaluating similarity of different models functional capabilities for IPIAS. For example, TAMM and TRIM are aimed at Resource Planning Act (RPA) type assessments, primarily on a national scale. IMPLAN uses counties as the smallest projection unit. PROGNOSIS predictions can be accomplished for a single stand or a group of stands; thus, it should be possible to construct IPIAS packages of different area scales.

Related to the question of the area scale for impact predictions is the question of deciding the use of or time frame for IPIAS predictions. IPIAS will probably be used to plan or schedule, for example; suppression activities, budget requests, field activities, and short or long term management regimes. Uses, then, define the time scale of the total scope of IPIAS.

The Integrated Pest Management Program for Southern Pine Beetle has suggested a manner in which to categorize prediction models (Leuschner 1979; Mason 1984). They suggest that all models be considered within a matrix defined by the interaction of time and area. This matrix (Figure 1) provides not only a means of categorizing models, but also a framework for making decisions about what an integrated impact system should include. In our view the scope of IPIAS is most likely represented by the cross-hatched cells of the matrix in Figure 1. Obviously the time frame of prediction is related to the ultimate use of these predictions in a specific application area (e.g., stand level suppression activities versus watershed silvicultural prescriptions). 
Figure 1 - Temporal and spatial scale matrix with which to categorize prediction models for their applicability in an integrated impact assessment systeml/.

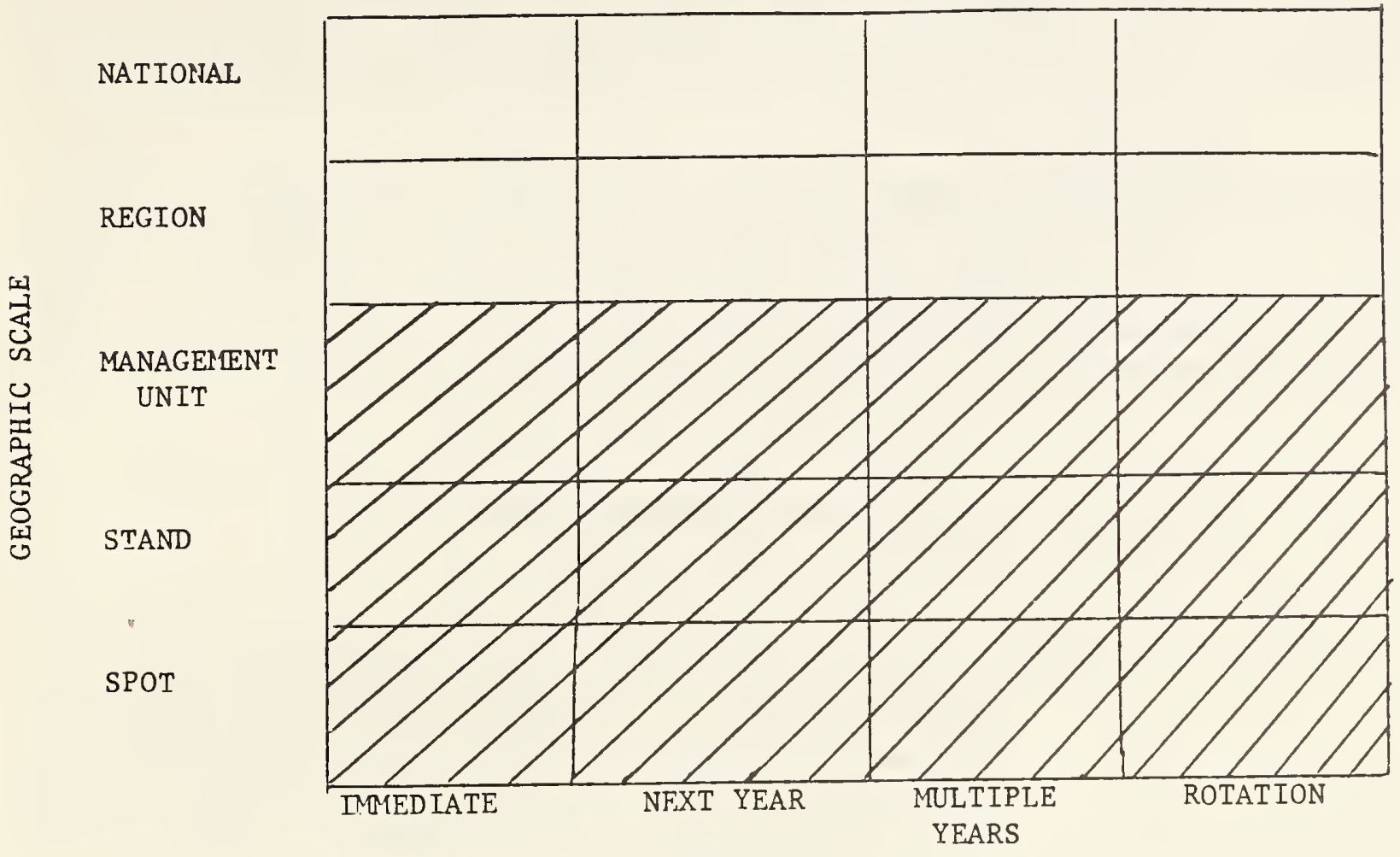

TIME SCALE

Cross-hatched cells - models addressing these temporal and spatial criteria were considered appropriate for inclusion in IPIAS. Conversely, the crosshatched cells also indicate the most probable location for IPIAS implementation.

1/From Leuschner (1979) and Mason (1984).

If benefit/cost analysis is to be ultimately used as a decision criterion for assessing the impacts of a control program for pests, then those models which afford the opportunity to integrate their outputs into benefit/cost analyses could be linked together as potential components of a particular operationalization of IPIAS. If, on the other hand, only general impact tradeoffs are to be assessed, then another different set of models can be linked together.

The process by which these models can be accessed by users and linked together in order to solve pest impact problems across a broad range of geographic and time requirements is problematic. However, the Southern Pine Beetle Decision Support System (SPBDSS) is an example of one way to accomplish this task (Rykiel et al. 1984). The Decision Support System (DSS) is an interactive computer program which acts as an operating "shell" or executive 
program to manage a library of models and information about them. This system can aid the user in defining the nature of his pest problem and can recommend predictive models to use in the problem solution (subprogram called FERRET). Further, it can automatically link appropriate models and coordinate the execution of them to provide comprehensive impact output. This DSS, or one similar to it, may well provide the basic operating framework for IPIAS.

During Fiscal Year 1985 a version of IPIAS was designed for the Red River District of the Nezperce National Forest in Idaho. This IPIAS includes a growth and yield simulator (PROGNOSIS), a mountain pine beetle contagion model, an elk migration model based upon habitat changes, a stream sedimentation model, and a fish habitat model. The entire IPIAS for this application area is driven from the geographic information system MOSS. This system was installed on the Forest's Data General minicomputer during July 1985 .

\section{CURRENT MODEL USE AND NEEDS}

A survey was designed to assess user characteristics, the need for pest impact models, and model interface requirements. This questionnaire was sent to 255 individuals in Forest Service Regions 1 and 6 . Each regional office, forest, and district were sent copies of the questionnaire. Questionnaires were also sent to specialists in timber management, recreation, hydrology, planning, wildlife, silviculture, and pest management. The intent of the questionnaire was to not only assess user interface needs, but also to find other models which were not discovered during the model inventory phase. 4 /

A total of 62 completed survey responses were returned. In a number of cases, one respondent represented the model use/needs of several individuals, i.e., survey recipients tended to pass the questionnaire on to their "resident model user". While the distribution list for the survey was comprehensive, there was no way to assure a complete return. Thus, the "representativeness" of the respondents is to some extent unknown, and there may be models and/or users in the targeted regions that were not captured by this survey.

The geographic distribution of survey respondents indicated good coverage of Regions 1 and 6. District, forest, and regional levels were all represented; not surprisingly, the large majority of respondents were silvicultural specialists. The low response rate from other forest specialists is consistent with the lack of avallable models for wildife, recreation, or aesthetics, that was reported above.

While every effort was made to survey all models and model users in Regions 1 and 6, there is no guarantee that every model or model use problem was identified. In combination, however, the direct interviews with knowledgeable individuals, the survey of model developers and expert users in both target

4/Detailed results of this user survey of model use and needs can be obtained by writing to Dr. G.J. Buhyoff, Professor of Forest Biometrics, Virginia Polytechnic Institute and State University, Blacksburg, VA 24061. 
regions; and the responses to the mailed survey provide a consistent and comprehensive profile of model use in forest management and planning. Again, a number of the "models" that were reported (or even rumored) to be in use were investigated and found to be, for example, either only "guidelines", not widely applicable, or not documented for general use. These were not included in this analysis which focused upon documented models which were, at least in principle, available for general use and which had been implemented.

It was very clear from this survey that the principal use of models in the target regions is for timber management. Forest silvicultural specialists far outnumber all other model users and "growth and yield" models are the most available, most used, and most sophisticated of the models identified by the survey. Indeed, as noted before, the use of models for wildlife, recreation, scenic quality, and range and water appears to be negligible or nonexistent. While some successful models have been developed in these areas (Buhyoff et a1. 1982; Schroeder and Daniel 1981), they are apparently not well known in these regions, and are currently not in use. Even in forest economics, where quantitative analysis and computer modeling has a more extensive history, little use of models was reported. Pest management reported substantial impact model use, but this was principally in very close relation to timber management activities.

PROGNOSIS and, to a much lesser extent, DFSIM, both growth and yield simulators, were the dominant models used in Regions 1 and 6 . Users of PROGNOSIS outnumbered the users of all other models by a wide margin. Again, this is due to the fact that PROGNOSIS has wide species and geographic application. User confidence in PROGNOSIS was generally high, though many users cited the need for improving the accuracy by better calibration to local conditions. At the same time, the relatively wide range of application was recognized as a strength, and there were several calls for an even greater range of application. In this context, the need for a less demanding, more user friendly interfact to PROGNOSIS, a concern cited by a number of users, becomes especially critical. The challenge to PROGNOSIS and other models for this user group is to provide the desired generality and local accuracy without introducing excessive input data requirements or mandating high computer sophistication on the part of the user.

Integration between models and data bases appears to be at a low level. There is some linkages between PROGNOSIS and one or another version of the standard forest inventory data bases. Linkages to geographic information systems are not presently available except where users have invented their own systems as such. Linkages among models in use is essentially nonexistent except for the PROGNOSIS extension models which are directly tied to the main PROGNOSIS growth and yield module. The most comprehensive effort at model linkage is represented by ECOSIM (a general ecosystem simulator), but this system is not generally available and essentially no use was reported in Regions 1 and 6 . Once again, respondents requests for improved user interface are relevant. Effective integration of models and data bases could reduce the need for repetitive and redundant data entry, parameter specifications and input/output control formats.

Most users felt that the costs of model use were reasonable, and virtually al1 agreed that costs were outweighed by benefits. Indications are that mode1 
projections are substantially influential in forest planning and management, and they may be even more so in the future. In this context, the essential lack and nonuse of systematic models for representing impacts on wildife, scenic quality, recreation, and other social and socioeconomic concerns necessarily implies rather low potential for these "other forest resources" to influence forest planning and management. Social impact models, or at least methods for developing such models, are available. Thus, this imbalance, which may be inconsistent with a number of public land management policies and regulations, need not continue. Survey results indicate, however, that there is little knowledge of the existing social impact models, little acknowledgement of the need for such models (except perhaps for wildlife), and in a few instances, outright antagonism toward the concept of modeling scenic or recreation values.

This survey of model use provides a basis for characterizing contemporary forest planning and management, at least as represented by Regions 1 and 6 . The use of computer implemented models of forest growth and mortality is intensive, widespread, and increasing for timber management and related pest management concerns. The influence of model projections on the formulation and selection of forest management alternatives is currently substantial, and promises to increase, especially given the growing availability of the computer hardware that is required for efficient use of these models. This scenario provides substantial impetus for the parallel development of systematic, computer implemented models to represent other forest management concerns. In this regard, Forest Pest Management has set an important example by using models of insect infestation and damage that are intimately interrelated with the dominant forest growth and yield models. The PROGNOSIS extensions, MPB, Western Spruce Budworm, Douglas-Fir Tussock Moth, and the MPB contagion model under development indicate a potentially fruitful approach to be followed by other resource specialists.

\section{CONCLUSION}

The results of the model inventory and user survey have important implications for the further development of the Integrated Pest Impact Assessment System. First, there is a recognized need for systematic impact assessment models to support forest planning and management. Models that have a reasonably wide range of applicability, that provide for accurate projections across stand types and site types, and that are easy for users to access and implement will have a large and eager clientele. Achieving such a system of models presents a considerable challenge, but significant progress is already presented by such efforts as ECOSIM and the PROGNOSIS family of models. An adequate base of models which can be linked to provide pest impact predictions for a variety of resources already exists. However, it will still be necessary to develop impact prediction models for recreation, esthetics, and other socioeconomic concerns if forest management and planning efforts are to be aided in their attempts to meet the requirements of RPA, NEPA, and the Multiple Use and Sustained Yield Act. 


\section{REFERENCES CITED}

Anonymous. 1983. Final report to USDA Forest Service, Forest Pest Management/Methods Application Group on a pest impact assessment system workshop. Milliken, C0, February 13-18, 1983.

Buhyoff, G.J., J.D. Wellman, and T.C. Daniel. 1982. Predicting scenic beauty for mountain pine beetle and western spruce budworm damaged forest vistas. Forest Science 28:827-838.

Buhyoff, G.J. and T.C. Daniel. 1984. Integrated pest impact assessment system: development and operations coordination. USDA Forest Service, Coop. Agreement 28-C4-320, FY84 Progress Report, September 1984.

Daniel, T.C., W.B. White, and D.0. Hunter. 1983. Integrated pest impact assessment system: an interface to a forest management information system. USDA Forest Service, Forest Pest Management/Methods Application Group, Fort Collins, Co, Rpt. No. 84-2, 22 pp.

Leuschner, W.A. 1979. Impact analysis, interpretation, and modeling. In Waters, W.E. (ed) Current Topics in forest entomology: selected papers from the XVth International Congress of Entomology. USDA Forest Service Gen. Tech. Rpt. Wo-8, U.S. Government Printing Office, Washington, D.C., pp. 50-53.

Mason, G.N. 1984 (revised June). Southern pine beetle predictions handbook. USDA Forest Service, Integrated Pest Management RD\&A Program, Southern Reg. Atlanta, GA.

Rykiel, E.J., M.C. Saunders, T.L. Wagner, D.K. Loh, R.H. Turnbow, L.C. Hu, P.E. Pully, and R.N. Coulson. 1984. Computer aided decision making and information accessing in pest management systems, with emphasis on the southern pine beetle. J. Econ. Entomology 77:1073-1082.

Schroeder, H.W. and T.C. Daniel. 1981. Progress in predicting the perceived scenic beauty of forest landscapes. Forest Science 27:71-80.

Thomas, J.W. (ed). 1979. Wildlife habitats in managed forests: the Blue Mountains of Oregon and Washington. USDA Forest Service, Ag. Handbook No. 533, $512 \mathrm{pp}$. 

APPENDIX A

First General Survey of Information on Prediction Models 


\title{
SURVEY OF CURRENT
}

STAND AND IMPACT MODELS

Please return this survey to:

\author{
Gregory J. Buhyoff \\ Associate Professor \\ Forest Biometrics \\ Department of Forestry \\ Virginia Tech \\ Blacksburg, VA 24061 \\ OR \\ Cal1: (703) 961-5148
}

We appreciate your assistance. If possible please return the survey or contact Greg Buhyoff by phone before May 11, 1984. 
1. Please list the forest stand, pest or other impact models you are familiar with either as a user, or a developer. Please send along any publications or copies of documentation you may have for these models.

2. Are any of these models specific to Mountain Pine Beetle and/or Lodgepole pine? If so, which ones?

3. Do you know of any new models or modifications of existing ones which are currently under development? If so, give model name or type and if possible the name and address of an appropriate person to contact.

4. Of the models listed in No. 1 above which ones are most extensively used and in what Regions or Forests?

5. Are you aware of any reliability or validity testing on any of the models you listed in No. 1? If so, can you provide any documentation or the name and address of a contact?

6a. What types of predictions (i.e., types of impacts, etc.) do the models listed in No. 1 above give?

6b. Are there, in your opinion, other information needs that the models in No. 1 above should address or outputs that they should give?

7. What types of data bases or Geographic Information Systems do the models in No. 1 above interface with?

8. What type of maintenance or calibration procedures are followed for the models you listed in No. 1 above?

9. How would you rate (in a general sense) the success of the models you listed in No. 1 above for longer range forest planning or short range management alternative? 



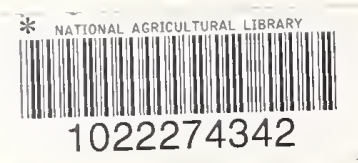

